OPEN ACCESS

Edited by: Johann Peter Gogarten, University of Connecticut,

United States

Reviewed by:

Francis Repoila,

Institut National de la Recherche

Agronomique (INRA), France

Nikolai Ravin,

Research Center for Biotechnology

(RAS), Russia

*Correspondence:

Manuel Espinosa

mespinosa@cib.csic.es

Chew Chieng Yeo

chewchieng@gmail.com

Specialty section:

This article was submitted to

Evolutionary and Genomic

Microbiology,

a section of the journal

Frontiers in Microbiology

Received: 09 May 2017

Accepted: 24 July 2017

Published: 04 August 2017

Citation:

Díaz-Orejas $R$, Espinosa $M$ and Yeo CC (2017) The Importance of the Expendable: Toxin-Antitoxin Genes

in Plasmids and Chromosomes.

Front. Microbiol. 8:1479.

doi: 10.3389/fmicb.2017.01479

\section{The Importance of the Expendable: Toxin-Antitoxin Genes in Plasmids and Chromosomes}

\author{
Ramón Díaz-Orejas ${ }^{1}$, Manuel Espinosa ${ }^{1 *}$ and Chew Chieng Yeo ${ }^{2 *}$ \\ ${ }^{1}$ Centro de Investigaciones Biológicas, Consejo Superior de Investigaciones Científicas (CSIC), Madrid, Spain, ${ }^{2}$ Faculty of \\ Medicine, Biomedical Research Centre, Universiti Sultan Zainal Abidin, Kuala Terengganu, Malaysia
}

Toxin-antitoxin (TA) genes were first reported in plasmids and were considered expendable genetic cassettes involved in the stable maintenance of the plasmid replicon by interfering with growth and/or viability of bacteria in which the plasmid was lost. TAs were later found in bacterial chromosomes and also in integrated mobile genetic elements; they were proposed to be involved in the bacterial response to stressful situations. At present, 100s of TAs have been identified and classified in up to six families (I to $\mathrm{VI}$ ), with those belonging to the type II (constituted by two protein components) being the most studied. Based on well-characterized examples of several type II TAs, we discuss in this review that irrespective of their locations in plasmids or chromosomes, TAs functionally overlap as indicated by: (i) in both locations they can mediate the maintenance of genetic elements to which they are physical linked, and (ii) they can induce persistence or virulence in response to stress situations. Examples of functional confluences in homologous TA systems with different locations are also given. We also consider whether the physiological role of TAs is due to their genetic organization as operons or to their inherent properties, like the short lifespan of the antitoxin component.

Keywords: toxin-antitoxin, plasmids, post-segregational killing, genomic islands, chromosome, bacterial virulence, persistence

\section{INTRODUCTION}

Toxin-antitoxin (TA) genes were initially discovered in two conjugative plasmids of Escherichia coli, F (Ogura and Hiraga, 1983) and R1 (Gerdes et al., 1986a; Bravo et al., 1988; Tsuchimoto et al., 1988), as cassette of two genes involved in stable maintenance of these plasmids; they were shown to participate in stable plasmid inheritance because they reduced either the viability or the growth of the cells that had lost the plasmid at the time of cell division (Bravo et al., 1988; Tsuchimoto et al., 1988). Killing of plasmid free segregants was termed post-segregational killing (PSK) (Gerdes et al., 1986b) and shown to be due to the decay of the more unstable antitoxin in plasmid-free cells and to the subsequent activation of the toxin in these cells. A role of plasmidic TAs in outcompeting compatible plasmids was later proposed (Cooper and Heinemann, 2000). TAs were also subsequently shown to be encoded by bacterial chromosomes and some of them integrated within mobile genetic elements (MGEs). One of the hypotheses to explain the presence and function of these TAs was that they participate in the response to stressful conditions 
(Christensen and Gerdes, 2003). At present, 100s of TAs have been identified and classified, depending on the nature and activity of antitoxins, in up to six types (type I to type VI), reviewed in Page and Peti (2016). To these toxin-antitoxin pairs can also be added Type II restriction enzymes and their cognate methylases: similar to conventional TAs, restrictionmodification systems can also be encoded in plasmids and enforce their maintenance by promoting PSK of plasmid-free cells (Yarmolinsky, 1995), although it must be emphasized that TA and RM complexes that have been characterized so far do not share an evolutionary origin (Mruk and Kobayashi, 2014). Type II TAs, which are constituted by two protein components, are the best characterized (Chan et al., 2016; Kędzierska and Hayes, 2016). Activation of TAs in response to stress was thought to be a way to either eliminate part of the population in benefit of the rest [i.e., "altruistic" cell death (Engelberg-Kulka and Glaser, 1999)], or to reduce the metabolic load during adverse conditions by slowing or arresting cell growth (Maisonneuve and Gerdes, 2014). Chromosomal TAs have also been associated with several bacterial processes, like biofilm formation, survival during infection of eukaryotic cells, defense against invading bacteriophages and entrance and exit into persistence (Goeders and Van Melderen, 2014; Kędzierska and Hayes, 2016; LobatoMárquez et al., 2016a). Since persistence is believed to be a major factor contributing to the chronic state of infections and tolerance to antibiotic treatments (Michiels et al., 2016), it was proposed that one of the roles of TAs was to contribute to dormancy, i.e., making the cells metabolically inactive (Pedersen et al., 2002; Christensen-Dalsgaard et al., 2010), a state that would lead to persistence due to triggering of the TAs (Maisonneuve et al., 2011; Maisonneuve and Gerdes, 2014). This attractive hypothesis was later considered as too simplistic (Ramisetty et al., 2016; Van Melderen and Wood, 2017). Since the initial discovery of TA systems as plasmid maintenance systems and their subsequent identification in the chromosome, many examples underline the functional confluence of these systems irrespective of their location. In the following sections we will try do discuss this confluence based on a few well-characterized examples of type II TA systems (see Table 1 for a summary of the TA systems covered in this review).

\section{PLASMID AND CHROMOSOMAL TOXIN-ANTITOXINS AS MEDIATORS OF POST-SEGREGATIONAL KILLING}

Several observations indicate the existence of functional overlaps of TAs placed on plasmids or on chromosomes. A role of the chromosomal TAs in stabilization of integrated MGE or adjacent chromosomal regions has been demonstrated (Wozniak and Waldor, 2009), a role that is similar to their function in maintaining plasmid stability through PSK (Hayes, 2003). A novel TA pair designated mosAT, was shown to be responsible for maintaining the integrity of the $\sim 100 \mathrm{~kb}$ SXT integrative and conjugative element (ICE) that confers resistance to multiple antibiotics in clinical isolates of Vibrio cholerae (Wozniak and Waldor, 2009). For a large MGE that can integrate, excise, and transfer to other bacteria, the SXT ICE is remarkably stable, with loss of ICE estimated at only 1 in $10^{7}$ cells (Wozniak and Waldor, 2009). The mosAT system has low basal transcriptional levels when SXT is integrated; however its expression is derepressed when SXT is in an extrachromosomal state and vulnerable to loss. Interestingly, a homolog of mosAT was located on an octopine-type $\mathrm{Ti}$ plasmid of Agrobacterium tumefaciens suggesting that this TA system may function to maintain the stability of plasmids as well as ICEs (Wozniak and Waldor, 2009). Another TA system designated sgiTA was recently shown to promote the maintenance of a multidrug resistant integrative and mobilizable Salmonella Genomic Island 1 (SGI1) in Salmonella enterica serovar Typhimurium (Huguet et al., 2016) in a manner similar to mosAT for SXT. Intriguingly, SGI1 is only transmissible in the presence of conjugative plasmids of the IncA/C group but paradoxically, SGI1 displayed incompatibility with the IncA/C plasmids. The sgiTA locus was shown to play an essential role in SGI1 stability particularly in the concomitant presence of a conjugative IncA/C plasmid when SGI1 is in an extrachromosomal state and is more likely to be lost (Huguet et al., 2016).

Further, elimination of cells that lose a chromosome has been demonstrated in the case of $V$. cholerae (Yuan et al., 2011). Like all vibrios, the $V$. cholerae genome consists of two chromosomes (Heidelberg et al., 2000), and the smaller chromosome II (ChrII, $1.07 \mathrm{Mbp}$ ) hosts a large $126 \mathrm{~kb}$ superintegron (SI) that gathers 100 s of diverse gene cassettes, including antibiotic resistance genes, and contains 17 TA systems (Iqbal et al., 2015). Each of these cassettes is associated with a target recombination sequence (the attC site) and in a SI, 100s of gene cassettes with their $a t t C$ sites are arranged in direct orientation, alluding to a likely inherent instability in these SIs. Nevertheless, SIs are remarkably stable, and in an earlier paper, it was elegantly demonstrated that two TA loci from the Vibrio vulnificus SI (relBE1 and parDE1) stabilize the SI and prevent large scale deletions from occurring when the SI was devoid of TA loci (Szekeres et al., 2007). Chromosome-specific mechanisms exist to ensure the proper segregation of the two $V$. cholerae chromosomes in daughter cells. In the $V$. cholerae ChrII, the parAB2 locus was essential for the partitioning of ChrII, and in a parAB2 deletion mutant, ChrII was mislocalized leading to a complete loss of the entire ChrII in a fraction of the population (Yamaichi et al., 2007). Cells that lost ChrII were non-viable and underwent characteristic cytological changes including cell enlargement, nucleoid condensation and degradation (Yamaichi et al., 2007). It was subsequently shown that the three ParE toxins encoded by their respective parDE TA loci in the SI of ChrII were responsible for the PSK of cells that lost ChrII, closely mimicking PSK mediated by plasmid-encoded homologs (Yuan et al., 2011). A recent paper showed that all 17 TA loci in the $V$. cholerae SI were functional, expressed from their own native promoters, and were very specific - i.e., there was no cross-interaction between non-cognate toxins and antitoxins (Iqbal et al., 2015). These advocate for a major role of these 17 TA loci in the stabilization of the $V$. cholerae SI and to prevent the emergence of cells that lack ChrII; in other words, much like their plasmid-encoded homologs, the $V$. cholerae chromosomal 
TABLE 1 | Summary of the location and functions of toxin-antitoxin (TA) systems covered in this review.

\begin{tabular}{|c|c|c|c|c|}
\hline TA & Host & Location of TA & Function & Reference \\
\hline MosAT & Vibrio cholerae & $\begin{array}{l}\text { Chromosomal; } \\
\text { integrative and } \\
\text { conjugative element } \\
\text { (ICE) }\end{array}$ & Stability of ICE & $\begin{array}{l}\text { Wozniak and Waldor, } \\
2009\end{array}$ \\
\hline SgiTA & Salmonella enterica serovar Typhimurium & $\begin{array}{l}\text { Chromosomal; } \\
\text { genomic island } 1\end{array}$ & $\begin{array}{l}\text { Stability of genomic } \\
\text { island }\end{array}$ & Huguet et al., 2016 \\
\hline RelBE1 ParDE1 & Vibrio vulnificus & $\begin{array}{l}\text { Chromosomal; } \\
\text { superintegron }\end{array}$ & Superintegron stability & Szekeres et al., 2007 \\
\hline $\begin{array}{l}\text { ParDE-1 } \\
\text { ParDE-2 } \\
\text { ParDE-3 } \\
\text { RelBE-1 } \\
\text { RelBE-2 } \\
\text { RelBE-3 } \\
\text { RelBE-4 } \\
\text { HigBA-1 } \\
\text { HigBA-2 } \\
\text { Phd-Doc } \\
\text { 0318-0319 } \\
\text { 0332-0333 } \\
\text { 0422-0423 } \\
\text { 0477-0478 } \\
\text { 0481-0482 } \\
\text { 0486-0487 } \\
\text { 0488-9489 }\end{array}$ & Vibrio cholerae & $\begin{array}{l}\text { Chromosome II, } \\
\text { superintegron }\end{array}$ & $\begin{array}{l}\text { Stability of } \\
\text { superintegron as well } \\
\text { as chromosome II }\end{array}$ & lqbal et al., 2015 \\
\hline $\begin{array}{l}\text { Epsilon-Zeta } \\
(\varepsilon-\zeta)\end{array}$ & Streptococcus pyogenes & Plasmid pSM19035 & Plasmid stability & Camacho et al., 2002 \\
\hline PezAT & Streptococcus pneumoniae & $\begin{array}{l}\text { Chromosomal, } \\
\text { pathogenicity island } 1\end{array}$ & $\begin{array}{l}\text { Stability of } \\
\text { pathogenicity island, } \\
\text { virulence factor }\end{array}$ & $\begin{array}{l}\text { Chan et al., 2014; } \\
\text { lannelli et al., } 2014\end{array}$ \\
\hline SezAT & Streptococcus suis & $\begin{array}{l}\text { Chromosomal; } \\
\text { pathogenicity island }\end{array}$ & $\begin{array}{l}\text { Stability of } \\
\text { pathogenicity island }\end{array}$ & Yao et al., 2015 \\
\hline AvrRxo1-Arc1 & Xanthomonas oryzae pv. oryzicola & Unknown & $\begin{array}{l}\text { Virulence factor (type III } \\
\text { secreted effector) }\end{array}$ & Triplett et al., 2016 \\
\hline $\mathrm{CcdAB}_{F}$ & Escherichia coli & Plasmid F & $\begin{array}{l}\text { Plasmid stability, } \\
\text { persistence }\end{array}$ & $\begin{array}{l}\text { Ogura and Hiraga, } \\
\text { 1983; Tripathi et al., } \\
2012\end{array}$ \\
\hline CcdABO157 & Escherichia coli O157:H7 & Chromosomal & Persistence & Gupta et al., 2017 \\
\hline $\begin{array}{l}\text { VapBC2 } \\
\text { CcdA } \\
\text { Ccd }\end{array}$ & Salmonella enterica serovar Typhimurium & Plasmid pLST & $\begin{array}{l}\text { Plasmid stability, } \\
\text { virulence Plasmid } \\
\text { stability }\end{array}$ & $\begin{array}{l}\text { Lobato-Márquez et al., } \\
\text { 2016b }\end{array}$ \\
\hline
\end{tabular}

TA loci are also agents of PSK (Yuan et al., 2011; Iqbal et al., 2015).

Conversely, it has been shown that plasmid-encoded TAs can contribute to overcome stress, induce persistence, and could increase survival of bacterial cells during infection (Helaine et al., 2014), functions that were initially attributed to chromosomal TAs (Lobato-Márquez et al., 2016a). PSK mediated by TAs following the loss of genetic information associated to a plasmid can be considered as a situation of stress, to which the cells react by toxin activation. Transient activation of the E. coli F-plasmid-encoded CcdB toxin enhance the generation of drugtolerant persister cells, and this process was found to be dependent on Lon protease and RecA (Tripathi et al., 2012). The F-plasmid-encoded $c c d A B_{\mathrm{F}}$ locus has been well-established as a plasmid maintenance system (Jaffe et al., 1985) and the finding that it plays a role in persistence expands its function as a transmissible persistence factor (Tripathi et al., 2012) (see below).

\section{PezAT AND ITS POTENTIAL ROLE IN VIRULENCE}

Two recent articles published in Frontiers (Chan and Espinosa, 2016; Lobato-Márquez et al., 2016b) underline the concept that phenotypes associated to plasmid- or to chromosomally encoded TAs do overlap because independent of their location, toxins target similar functions and the TA operons are regulated and induced by similar conditions. The first example is provided by the pneumococcal pezAT operon (Khoo et al., 2007; Chan and Espinosa, 2016). The two genes constituting it are placed in the putative mobilizable pathogenicity island 1 (pneumococcal 
pathogenicity island 1, PPI1) and that is found in nearly half of capsulated (virulent) Streptococcus pneumoniae strains (Chan et al., 2012). In some strains there is a second copy of the operon, located on the putative ICE Tn5253. A close homolog of the PezAT pair is the Epsilon-Zeta TA, which was discovered in the broad host-range plasmid pSM19035 of Streptococcus pyogenes (Camacho et al., 2002). Epsilon-Zeta differs from PezAT as the Epsilon antitoxin does not perform the transcriptional regulation of the operon, but rather by a third component, Omega, which also regulates the transcription of other genes encoded by the pSM19025 plasmid. In the pezAT operon, the PezA antitoxin performs the autoregulatory role (Khoo et al., 2007). EpsilonZeta plays an essential role in maintaining the stability of plasmid pSM19035 via PSK.

The Zeta/PezT toxins target the cell wall synthesis machinery by phosphorylating the peptidoglycan precursor, UDP- $N$ acetylglucosamine (UNAG) at the $3^{\prime}-\mathrm{OH}$ group of the $\mathrm{N}$-acetylglycosamine moiety. The phosphorylated product, UDP$N$-acetylglucosamine-3-phosphate (UNAG-3P), accumulates in the cytosol and inhibits MurA, which is the essential enzyme that catalyzes the initial step in peptidoglycan synthesis (Mutschler and Meinhart, 2011; Mutschler et al., 2011). Nevertheless, it was proposed that reduction in the UNAG levels is just one of several responses that is triggered by Zeta/PezT expression in response to stress (Tabone et al., 2014). The pezAT operon may play a role in stabilizing the MGE within the pneumococcal host (Chan et al., 2014; Iannelli et al., 2014). Further, a close homolog of pezAT was discovered in Streptococcus suis (designated sezAT), which was shown to be important for the stable inheritance of the Pathogenicity Island 1 (SsPI-1) (Yao et al., 2015). Pneumococcal strains that carry pezAT exhibit increased virulence; further, deletion of the operon led to pneumococcal cells exhibiting increased resistance to $\beta$-lactam antibiotics and to increased ability to take up homologous DNA by enhancing genetic competence (Chan and Espinosa, 2016). How PezT functions to increase pneumococcal virulence is currently unknown but it was postulated that activation of PezT during environmental stresses or the course of infection would result in inhibition of cell wall synthesis and subsequent lysis of a subpopulation of pneumococcal cells (Mutschler and Meinhart, 2011, 2013). The lysis of these cells would lead to the release of cellular components detrimental to the infected host such as pneumolysin. Interestingly, recent papers showed that a PezT/Zeta homolog, designated AvrRxo1 from the plant pathogen Xanthomonas oryzae pv. oryzicola functions as a type III-secreted virulence factor which is toxic in plants and is bacteriostatic when expressed in E. coli (Han et al., 2015; Triplett et al., 2016). An AvrRxo1 homolog from myxobacterium was also shown to trigger rapid cell death response in tobacco (Triplett et al., 2016). Intriguingly, although the AvrRxol toxin was found to be a nucleotide kinase, its target is not UNAG like PezT/Zeta but rather, the coenzyme nicotinamide adenine dinucleotide (NAD) and its biochemical precursor, nicotinic acid adenine dinucleotide (NAAD) leading to the formation of unusual $3^{\prime}$-phosphorylated products, $3^{\prime}$ NADP and $3^{\prime}$-nicotinic acid adenine dinucleotide phosphate (3'-NADDP) (Schuebel et al., 2016). A recent paper showed that $3^{\prime}$-NADP accumulates upon expression of AvrRxo1 in tobacco and rice leaves infected with AvrRxo1-expressing strains of Xanthomonas oryzae, thus indicating that the AvrRxol effector/toxin targets the coenzyme and redox carrier essential for central metabolic function of the host. However, the actual mechanism of $3^{\prime}$-NADP accumulation in planta is currently unknown as NAD and the conventional cofactor, $2^{\prime}$-NADP, are needed in $100 \mathrm{~s}$ of essential reactions in the cell (Shidore et al., 2017). Hence, it could be possible that PezT/Zeta not only help in triggering the lysis of pneumococcal cells, the toxin itself may also be detrimental to the infected host cells. Indeed, it was recently shown that expression of the pneumococcal pezT toxin in the eukaryotic microalgae Chlorella vulgaris is lethal, leading to cellular damage and lysis ( $\mathrm{Ng}$ et al., 2016). We await experimental results that would indicate if expression of PezT/Zeta in mammalian cells would be equally detrimental.

\section{FUNCTIONAL OVERLAPS BETWEEN CHROMOSOMAL AND PLASMID-ENCODED TA SYSTEMS}

The second example is related to the role of TAs of Salmonella enterica serovar Typhimurium carrying the virulence plasmid pLST during bacterial infection (Lobato-Márquez et al., 2016b). One of the two TAs encoded by plasmid pLST is vapBC $C_{S T}$. This particular TA contributes to the successful colonization of recipient cells during infection, in conjunction with other type I and type II TAs encoded by the Salmonella chromosome (LobatoMárquez et al., 2015). In addition to its role during infection, the plasmidic copy of $v a p B C_{S T}$ contributes to the maintenance of the plasmid (Lobato-Márquez et al., 2016b). Interestingly, the chromosomal copy of this particular TA seems to be inactive, so that the role in infection was taken up by the plasmid-encoded copy. Curiously enough, the VapC toxin of vapBC2 $2_{S T}$ is active as a toxin, indicating that stabilization of pLST could be due to PSK (Lobato-Márquez et al., 2015).

An interesting example showing that location is compatible with different functions is provided by the first type II locus described, the $c c d A B_{\mathrm{F}}$ operon encoded by plasmid $\mathrm{F}$ (Jaffe et al., 1985). This operon was reported to contribute to plasmid maintenance by killing plasmid free-segregants; PSK was the result of Lon protease-mediated degradation of the CcdA antitoxin and the subsequent activation of the antitopoisomerase activity of the toxin $\mathrm{CcdB}$ (Ogura and Hiraga, 1983). In addition to its role in plasmid maintenance, $c c d A B_{\mathrm{F}}$ was shown to contribute to bacterial persistence (Tripathi et al., 2012), a role that was also proposed for several chromosomal TA systems (Maisonneuve et al., 2011) and that has been questioned as reductionist recently (Ramisetty et al., 2016; Van Melderen and Wood, 2017). Furthermore, the $c c d A B_{S T}$ system of plasmid pLST seems to participate in plasmid maintenance beyond PSK because, in spite of carrying a single point mutation that inactivates the anti-topoisomerase activity of $\mathrm{CcdB}_{\mathrm{ST}}$, it contributes significantly to the stabilization of the virulence plasmid by a yet to be identified mechanism 
(Lobato-Márquez et al., 2016b). Functional interactions between co-existing $c c d$ systems in plasmid and chromosome reported to be present in the pathogenic E. coli strain O157:H7 added further versatility to this system (Wilbaux et al., 2007). The chromosomally encoded $c c d A B$ genes, like the plasmidic ones, has a toxin that target DNA gyrase and an antitoxin that is degraded by the Lon protease; however, both TAs seem to have evolved to achieve different functions: only the plasmidic antitoxin is able to neutralize the chromosomal toxin but not vice versa, and only the plasmidic TA is able to promote plasmid maintenance by PSK (Wilbaux et al., 2007). Nevertheless, a recent paper has shown that the chromosomal $c c d A B_{\mathrm{O} 157}$ system from E. coli O157:H7 also function in the formation of persister cells much like its F-plasmid-encoded counterpart even though the $\mathrm{CcdB}_{\mathrm{O} 157}$ toxin displayed lower toxicity and has fivefold lower affinity for DNA gyrase compared to $\mathrm{CcdB}_{\mathrm{F}}$ (Gupta et al., 2017).

Plasmid maintenance linked to the coordination of TAs with plasmid replication was initially reported by the DiazOrejas laboratory on the kis-kid TA encoded by plasmid R1 (Ruiz-Echevarría et al., 1995a,b), and further analyzed (Pimentel et al., 2005; López-Villarejo et al., 2012, 2015). Additional work revealed a further coordination of the kis-kid TA with cell cycle functions (Pimentel et al., 2014). On the whole the above work supports that, failures in plasmid $\mathrm{R} 1$ replication reduces the levels of the Kis antitoxin and increases the activity of the Kid toxin. This results in: (i) the rescue of plasmid replication mediated by Kid-dependent decrease in the expression levels of CopB, a secondary inhibitor of plasmid replication, and (ii) the decrease in the levels of key cell division proteins that allows the rescue of plasmid replication before cell division can occur.

Targeting by RNase toxins of mRNAs, tRNAs and rRNAs impact and remodel protein synthesis and are key to the stress response mediated by TAs (reviewed by Moll and EngelbergKulka, 2012; Cruz and Woychik, 2015). Targeting tRNA and remodeling of protein synthesis profile seem to be a general mechanism of stress response. Indeed, a recent publication (Chionh et al., 2016) reveals a mechanism related to response to oxidative stress and induction of persistence in Mycobacterium bovis. The mechanism implies modification of the tRNA anticodons for threonine or leucine. Due to these modifications, the tRNA will enable the efficient translation of particular proteins related to the oxidative stress response. These will lead, in turn, to: (i) remodeling the protein synthesis potential of the cell to respond to oxidative stress; (ii) preferential synthesis of a set of stress response proteins, and (iii) induction of persistence.

\section{REFERENCES}

Bravo, A., Ortega, S., De Torrontegui, G., and Díaz, R. (1988). Killing of Escherichia coli cells modulated by components of the stability system ParD of plasmid R1. Mol. Gen. Genet. 215, 146-151. doi: 10.1007/BF00331316

Camacho, A. G., Misselwitz, R., Behlke, J., Ayora, S., Welfle, K., Meinhart, A., et al. (2002). In vitro and in vivo stability of the epsilon $z_{2}$ eta $_{2}$ protein complex of the broad host-range Streptococcus pyogenes pSM19035 addiction system. Biol. Chem. 383, 1701-1713. doi: 10.1515/BC.2002.191

Chan, W. T., and Espinosa, M. (2016). The Streptococcus pneumoniae pezAT toxinantitoxin system reduces $\beta$-lactam resistance and genetic competence. Front. Microbiol. 7:1322. doi: 10.3389/fmicb.2016.01322
Most interestingly these stress response mechanisms seem to be universal and are shared by prokaryotes and eukaryotes. Induction of persistence by TAs in response to stress also involves reduction of the protein synthesis potential and selective synthesis of proteins required to achieve survival to the stressinducing agent (reviewed by Moll and Engelberg-Kulka, 2012).

\section{CONCLUDING REMARKS}

TAs were proposed to be part of the accessory genome but as more and more details of their biological function are uncovered, the importance of these (apparently) expendable genetic entities to the lifestyle of their hosts are becoming clearer. As we have shown in this review, the biological functions of TAs do overlap irrespective of their location in their host genome - i.e., whether they are chromosomally encoded or plasmid-borne. Initially implicated in maintaining the stability of plasmids via PSK, TAs have since been shown to mediate the stability of genomic islands and even chromosome II of $V$. cholerae by PSK. Both plasmidand chromosomally encoded TAs have also been implicated in persistence and virulence of several pathogens. It is thus clear that these hitherto "expendable" genetic loci have successfully integrated into their hosts' cellular regulatory network, enabling their hosts to better adapt to their distinctive environmental niches.

\section{AUTHOR CONTRIBUTIONS}

RD-O, ME, and CCY designed the outline of the review. $\mathrm{RD}-\mathrm{O}$ wrote the first draft, and all authors worked on it until the production of the final version.

\section{FUNDING}

While this review was being written, the authors participated in projects funded by MINECO-BIO2015-69085-REDC (to RD-O and ME) and FRGS/1/2016/SKK11/UNISZA/01/1 (to CCY).

\section{ACKNOWLEDGMENT}

Thanks are due to Damián Lobato-Márquez for his critical reading of the manuscript.

Chan, W. T., Espinosa, M., and Yeo, C. C. (2016). Keeping the wolves at bay: antitoxins of prokaryotic type II toxin-antitoxin systems. Front. Mol. Biosci. 3:9. doi: 10.3389/fmolb.2016.00009

Chan, W. T., Moreno-Córdoba, I., Yeo, C. C., and Espinosa, M. (2012). Toxinantitoxin genes of the gram-positive pathogen Streptococcus pneumoniae: so few and yet so many. Microbiol. Mol. Biol. Rev. 76, 773-791. doi: 10.1128/MMBR. 00030- 12

Chan, W. T., Yeo, C. C., Sadowy, E., and Espinosa, M. (2014). Functional validation of putative toxin-antitoxin genes from the Grampositive pathogen Streptococcus pneumoniae: phd-doc is the fourth bona-fide operon. Front. Microbiol. 5:677. doi: 10.3389/fmicb.2014. 00677 
Chionh, Y. H., Mcbee, M., Babu, I. R., Hia, F., Lin, W., Zhao, W., et al. (2016). tRNA-mediated codon-biased translation in mycobacterial hypoxic persistence. Nat. Commun. 7:13302. doi: 10.1038/ncomms13302

Christensen, S. K., and Gerdes, K. (2003). RelE toxins from bacteria and archaea cleave mRNAs on translating ribosomes, which are rescued by tmRNA. Mol. Microbiol. 48, 1389-1400. doi: 10.1046/j.1365-2958.2003.03512.x

Christensen-Dalsgaard, M., Jørgensen, M. G., and Gerdes, K. (2010). Three new RelE-homologous mRNA interferases of Escherichia coli differentially induced by environmental stresses. Mol. Microbiol. 75, 333-348. doi: 10.1111/j.13652958.2009.06969.x

Cooper, T. F., and Heinemann, J. A. (2000). Postsegregational killing does not increase plasmid stability but acts to mediate the exclusion of competing plasmids. Proc. Natl. Acad. Sci. U.S.A. 97, 12643-12648. doi: 10.1073/pnas. 220077897

Cruz, J. W., and Woychik, N. A. (2015). tRNAs taking charge. Pathog. Dis. 74:ftv117. doi: 10.1093/femspd/ftv117

Engelberg-Kulka, H., and Glaser, G. (1999). Addiction modules and programmed cell death and antideath in bacterial cultures. Annu. Rev. Microbiol. 53, 43-70. doi: 10.1146/annurev.micro.53.1.43

Gerdes, K., Bech, F. W., Jørgensen, S. T., Løbner-Olesen, A., Rasmussen, P. B., Atlung, T., et al. (1986a). Mechanism of postsegregational killing by the hok gene product of the parB system of plasmid R1 and its homology with the relF gene product of the Escherichia coli relB operon. EMBO J. 5, 2023-2029.

Gerdes, K., Rasmussen, P. B., and Molin, S. (1986b). Unique type of plasmid maintenance function: postsegregational killing of plasmid-free cells. Proc. Natl. Acad. Sci. U.S.A. 83, 3116-3120.

Goeders, N., and Van Melderen, L. (2014). Toxin-antitoxin systems as multilevel interaction systems. Toxins 6, 304-324. doi: 10.3390/toxins6010304

Gupta, K., Tripathi, A., Sahu, A., and Varadarajan, R. (2017). Contribution of the chromosomal $c c d A B$ operon to bacterial drug tolerance. J. Bacteriol. doi: 10.1128/jb.00397-17 [Epub ahead of print].

Han, Q., Zhou, C., Wu, S., Liu, Y., Triplett, L., Miao, J., et al. (2015). Crystal structure of Xanthomonas AvrRxo1-ORF1, a Type III effector with a polynucleotide kinase domain, and its interactor AvrRxo1-ORF2. Structure 23, 1900-1909. doi: 10.1016/j.str.2015.06.030

Hayes, F. (2003). Toxins-antitoxins: plasmid maintenance, programmed cell death, and cell cycle arrest. Science 301, 1496-1499. doi: 10.1126/science.1088157

Heidelberg, J. F., Eisen, J. A., Nelson, W. C., Clayton, R. A., Gwinn, M. L., Dodson, R. J., et al. (2000). DNA sequence of both chromosomes of the cholera pathogen Vibrio cholerae. Nature 406, 477-483. doi: 10.1038/35020000

Helaine, S., Cheverton, A. M., Watson, K. G., Faure, L. M., Matthews, S. A., and Holden, D. W. (2014). Internalization of Salmonella by macrophages induces formation of nonreplicating persisters. Science 343, 204-208. doi: 10.1126/ science. 1244705

Huguet, K. T., Gonnet, M., Doublet, B., and Cloeckaert, A. (2016). A toxin antitoxin system promotes the maintenance of the IncA/C-mobilizable Salmonella Genomic Island 1. Sci. Rep. 6:32285. doi: 10.1038/srep32285

Iannelli, F., Santoro, F., Oggioni, M. R., and Pozzi, G. (2014). Nucleotide sequence analysis of integrative conjugative element Tn5253 of Streptococcus pneumoniae. Antimicrob. Agents Chemother. 58, 1235-1239. doi: 10.1128/AAC. 01764-13

Iqbal, N., Guérout, A.-M., Krin, E., Le Roux, F., and Mazel, D. (2015). Comprehensive functional analysis of the 18 Vibrio cholerae N16961 toxinantitoxin systems substantiates their role in stabilizing the superintegron. J. Bacteriol. 197, 2150-2159. doi: 10.1128/jb.00108-15

Jaffe, A., Oruga, T., and Hiraga, S. (1985). Effects of the $c c d$ function of the F plasmid on bacterial growth. J. Bacteriol. 163, 841-849.

Kędzierska, B., and Hayes, F. (2016). Emerging roles of Toxin-Antitoxin modules in bacterial pathogenesis. Molecules 21:E790. doi: 10.3390/molecules 21060790

Khoo, S. K., Loll, B., Chan, W. T., Shoeman, R. L., Ngoo, L., Yeo, C. C., et al. (2007). Molecular and structural characterization of the PezAT chromosomal toxinantitoxin system of the human pathogen Streptococcus pneumoniae. J. Biol. Chem. 282, 19606-19618. doi: 10.1074/jbc.M701703200

Lobato-Márquez, D., Díaz-Orejas, R., and García-Del Portillo, F. (2016a). Toxin-antitoxins and bacterial virulence. FEMS Microbiol. Rev. 40, 592-609. doi: 10.1093/femsre/fuw022

Lobato-Márquez, D., Molina-García, L., Moreno-Córdoba, I., García-Del Portillo, F., and Díaz-Orejas, R. (2016b). Stabilization of the virulence plasmid pSLT of Salmonella Typhimurium by three maintenance systems and its evaluation by using a new stability test. Front. Mol. Biosci. 3:66. doi: $10.3389 /$ fmolb. 2016.00066

Lobato-Márquez, D., Moreno-Córdoba, I., Figueroa, V., Díaz-Orejas, R., and García-Del Portillo, F. (2015). Distinct type I and type II toxin-antitoxin modules control Salmonella lifestyle inside eukaryotic cells. Sci. Rep. 5:9374. doi: $10.1038 /$ srep09374

López-Villarejo, J., Diago-Navarro, E. E., Hernández-Arriaga, A. M., and DíazOrejas, R. (2012). Kis antitoxin couples plasmid R1 replication and parD (kis, kid) maintenance modules. Plasmid 67, 118-127. doi: 10.1016/j.plasmid.2011. 12.015

López-Villarejo, J., Lobato-Márquez, D., and Díaz-Orejas, R. (2015). Coupling between the basic replicon and the Kis-Kid maintenance system of plasmid R1: modulation by Kis antitoxin levels and involvement in control of plasmid replication. Toxins 7, 478-492. doi: 10.3390/toxins7020478

Maisonneuve, E., and Gerdes, K. (2014). Molecular mechanisms underlying bacterial persisters. Cell 157, 539-548. doi: 10.1016/j.cell.2014.02.050

Maisonneuve, E., Shakespeare, L. J., Jørgensen, M. G., and Gerdes, K. (2011). Bacterial persistence by RNA endonucleases. Proc. Natl. Acad. Sci. U.S.A. 108, 13206-13211. doi: 10.1073/pnas.1100186108

Michiels, J. E., Van Den Bergh, B., Verstraeten, N., and Michiels, J. (2016). Molecular mechanisms and clinical implications of bacterial persistence. Drug Resist. Updat. 29, 76-89. doi: 10.1016/j.drup.2016.10.002

Moll, I., and Engelberg-Kulka, H. (2012). Selective translation during stress in Escherichia coli. Trends Biochem. Sci. 11, 493-498. doi: 10.1016/j.tibs.2012. 07.007

Mruk, I., and Kobayashi, I. (2014). To be or not to be: regulation of restrictionmodification systems and other toxin-antitoxin systems. Nucleic Acids Res. 42, 70-86. doi: 10.1093/nar/gkt711

Mutschler, H., Gebhardt, M., Shoeman, R. L., and Meinhart, A. (2011). A novel mechanism of programmed cell death in bacteria by toxin-antitoxin systems corrupts peptidoglycan synthesis. PLoS Biol. 9:e1001033. doi: 10.1371/journal. pbio. 1001033

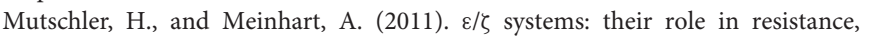
virulence, and their potential for antibiotic development. J. Mol. Med. 89, 1183-1194. doi: 10.1007/s00109-011-0797-4

Mutschler, H., and Meinhart, A. (2013). "Type II toxin-antitoxin loci: the epsilon/zeta family," in Prokaryotic Toxin-Antitoxins, ed. K. Gerdes (Berlin: Springer), 205-223.

Ng, S. L., Harikrishna, J. A., Abu Bakar, F., Yeo, C. C., and Cha, T. S. (2016). Heterologous expression of the Streptococcus pneumoniae yoeB and pezT toxin genes is lethal in Chlorella vulgaris. Algal Res. 19, 21-29. doi: 10.1016/j.algal. 2016.07.011

Ogura, T., and Hiraga, S. (1983). Mini-F plasmid genes that couple host cell division to plasmid proliferation. Proc. Natl. Acad. Sci. U.S.A. 80, 4784-4788. doi: $10.1073 /$ pnas.80.15.4784

Page, R., and Peti, W. (2016). Toxin-antitoxin systems in bacterial growth arrest and persistence. Nat. Chem. Biol. 12, 208-214. doi: 10.1038/nchembio.2044

Pedersen, K., Christensen, K. S., and Gerdes, K. (2002). Rapid induction and reversal of a bacteriostatic condition by controlled expression of toxins and antitoxins. Mol. Microbiol. 45, 501-510. doi: 10.1046/j.1365-2958.2002.03027.x

Pimentel, B., Madine, M. A., and De La Cueva-Mendez, G. (2005). Kid cleaves specific mRNAs at UUACU sites to rescue the copy number of plasmid R1. EMBO J. 24, 3459-3469. doi: 10.1038/sj.emboj.7600815

Pimentel, B., Nair, R., Bermejo-Rodríguez, C., Preston, M. A., Agu, C. A., Wang, X., et al. (2014). Toxin Kid uncouples DNA replication and cell division to enforce retention of plasmid R1 in Escherichia coli cells. Proc. Natl. Acad. Sci. U.S.A. 111, 2734-2739. doi: 10.1073/pnas.1308241111

Ramisetty, B. C. M., Ghosh, D., Roy Chowdhury, M., and Santhosh, R. S. (2016). What Is the link between stringent response, endoribonuclease encoding Type II Toxin-Antitoxin systems and persistence? Front. Microbiol. 7:1882. doi: $10.3389 /$ fmicb.2016.01882

Ruiz-Echevarría, M. J., De La Torre, M. A., and Díaz-Orejas, R. (1995a). A mutation that decreases the efficiency of plasmid R1 replication leads to the activation of parD, a killer stability system of the plasmid. FEMS Microbiol. Lett. 130, 129-135. doi: 10.1111/j.1574-6968.1995.tb07709.x

Ruiz-Echevarría, M. J., Giménez-Gallego, G., Sabariegos-Jareño, R., and DíazOrejas, R. (1995b). Kid, a small protein of the parD stability system of plasmid 
$\mathrm{R} 1$ is an inhibitor of DNA replication acting at the initiation of DNA synthesis. J. Mol. Biol. 247, 568-577. doi: 10.1016/S0022-2836(05)80138-X

Schuebel, F., Rocker, A., Edelmann, D., Schessner, J., Brieke, C., and Meinhart, A. (2016). $3^{\prime}$-NADP and $3^{\prime}$-NAADP, two metabolites formed by the bacterial Type III effector AvrRxo1. J. Biol. Chem. 291, 22868-22880. doi: 10.1074/jbc.M116. 751297

Shidore, T., Broeckling, C. D., Kirkwood, J. S., Long, J. J., Miao, J., Zhao, B., et al. (2017). The effector AvrRxol phosphorylates NAD in planta. PLOS Pathog. 13:e1006442. doi: 10.1371/journal.ppat.1006442

Szekeres, S., Dauti, M., Wilde, C., Mazel, D., and Rowe-Magnus, D. A. (2007). Chromosomal toxin-antitoxin loci can diminish large-scale genome reductions in the absence of selection. Mol. Microbiol. 63, 1588-1605. doi: 10.1111/j.13652958.2007.05613.x

Tabone, M., Lioy, V. S., Ayora, S., Machón, C., and Alonso, J. C. (2014). Role of Toxin $\zeta$ and starvation responses in the sensitivity to antimicrobials. PLoS ONE 9:e86615. doi: 10.1371/journal.pone.0086615

Tripathi, A., Dewan, P. C., Barua, B., and Varadarajan, R. (2012). Additional role for the ccd operon of F-plasmid as a transmissible persistence factor. Proc. Natl. Acad. Sci. U.S.A. 109, 12497-12502. doi: 10.1073/pnas.1121217109

Triplett, L. R., Shidore, T., Long, J., Miao, J., Wu, S., Han, Q., et al. (2016). AvrRxol is a bifunctional Type III secreted effector and Toxin-Antitoxin system component with homologs in diverse environmental contexts. PLoS ONE 11:e0158856. doi: 10.1371/journal.pone.0158856

Tsuchimoto, S., Ohtsubo, H., and Ohtsubo, E. (1988). Two genes, pemK and pemI, responsible for stable maintenance of resistance plasmid R100. J. Bacteriol. 170, 1461-1466. doi: 10.1128/jb.170.4.1461-1466.1988

Van Melderen, L., and Wood, T. K. (2017). Commentary: What is the link between stringent response, endoribonuclease encoding Type II ToxinAntitoxin systems and persistence? Front. Microbiol. 8:191. doi: 10.3389/fmicb. 2017.00191
Wilbaux, M., Mine, N., Guerout, A.-M., Mazel, D., and Van Melderen, L. (2007). Functional interactions between coexisting toxin-antitoxin systems of the $c c d$ family in Escherichia coli O157:H7. J. Bacteriol. 189, 2712-2719. doi: 10.1128/ jb.01679-06

Wozniak, R. A. F., and Waldor, M. K. (2009). A toxin-antitoxin system promotes the maintenance of an integrative conjugative element. PLoS Genet. 5:e1000439. doi: 10.1371/journal.pgen.1000439

Yamaichi, Y., Fogel, M. A., and Waldor, M. K. (2007). par genes and the pathology of chromosome loss in Vibrio cholerae. Proc. Natl. Acad. Sci. U.S.A. 104, 630-635. doi: 10.1073/pnas.0608341104

Yao, X., Chen, T., Shen, X., Zhao, Y., Wang, M., Rao, X., et al. (2015). The chromosomal SezAT toxin-antitoxin system promotes the maintenance of the SsPI-1 pathogenicity island in epidemic Streptococcus suis. Mol. Microbiol. 98, 243-257. doi: $10.1111 / \mathrm{mmi} .13116$

Yarmolinsky, M. (1995). Programed cell death in bacterial populations. Science 267, 836-838. doi: 10.1126/science.7846528

Yuan, J., Yamaichi, Y., and Waldor, M. K. (2011). The three Vibrio cholerae chromosome II-encoded ParE toxins degrade chromosome I following loss of chromosome II. J. Bacteriol. 193, 611-619. doi: 10.1128/jb.01185-10

Conflict of Interest Statement: The authors declare that the research was conducted in the absence of any commercial or financial relationships that could be construed as a potential conflict of interest.

Copyright (C) 2017 Díaz-Orejas, Espinosa and Yeo. This is an open-access article distributed under the terms of the Creative Commons Attribution License (CC BY). The use, distribution or reproduction in other forums is permitted, provided the original author(s) or licensor are credited and that the original publication in this journal is cited, in accordance with accepted academic practice. No use, distribution or reproduction is permitted which does not comply with these terms. 